\title{
Hubungan Kegiatan Ekstrakurikuler Pramuka dengan Prestasi Belajar Siswa di SMA N 1 X Koto Singkarak
}

\author{
Oki Saputra ${ }^{1}$, Hadiyanto ${ }^{2}$, Ahmad Sabandi $^{3}$, Lusi Susanti ${ }^{4}$
}

1,2,3,4Administrasi Pendidikan, Universitas Negeri Padang

Oki Saputra ${ }^{1}$, e-mail: okis2026@gmail.com

Hadiyanto ${ }^{2}$, e-mail: hadiyanto@fip.unp.ac.id

Ahmad Sabandi ${ }^{3}$, e-mail: $\underline{\text { sabandi@fip.unp.ac.id }}$

Lusi Susanti ${ }^{4}$, e-mail: lusy_mp@yahoo.com

\begin{abstract}
This reseach is the meaning to get information on the relationship of scout ectrakurikular activities to student achievement in SMA N 1 X Koto Singkarak. The purposed of this studi is to obtan informaton on: 1) Student achievement, 2) Scout extracurricular activities and 3) The relationship of Scout extracurricular activities to student learning achievement. The populati in this studi is the whole student who follows the extracurricular scouts in SMAN 1 X Koto Singkarak amounted to 228 people. The sample in this studi amouted to 66 peoples using the Slovin formula and take with proportonal stratfied random sampling techniq. The reseach instrumen use is questionaire using the Likertscale model with 5 answers the answers that have been teste validitiy and reliabilitiy by using SPSS version 16.0. Data analyze usng product moment corelation formula. The result of data analysis show 1) the achievement of low-category student's study is $67.8 \%$ 2) Excillant activity of scouting category is quite good $73 \%$ and 3 ) There is a significant relationshipp between scout extracurricular activities on student achievement in SMAN 1 X Koto Singkarak R hitung at $0.728>\mathrm{R}$ tabel 0.24 and Thacung value 8,495> Ttable 1.980 at the level of confidence $95 \%$ of this study showed that there is a mean relationship on the scout extracurricular activities to student achievement at SMAN 1 X Koto Singkarak. This means that the scout extracuricular activites are one of the factor that affect student achievement in SMAN 1 x Koto Singkarak.
\end{abstract}

\begin{abstract}
Abstrak
Riset ini maksud nya untuk mendapatkan informasi adakah hubungan kegiatan ektrakurikuler pramuka dengan prestasi belajar murid di SMA N 1 X Koto Singkark. Tujuan risrch ini untuk mengtahui gambaran: 1) prestasi belajar siswa,2) kegiatan ekstrakurikuler pramuka dan 3) hubunga kegiatan ekstrakurikuler pramuka dgn prestasi belajar muid. Populasionnya adalah seluruh murid yang mengikuti ekstrakurikuler pramuka di SMAN 1 X Koto Singkarak berjumlah 228 orang. Sample yaitu 66 siswa didapat dengan rumus slovin dan diambil dengan teknique proportional stratified random sampling.. Instrumen reserch dengan angket model skala liker dan 5 jawaban yang diuji valididtas dana relibilitasnya dengan antuan SPSS 16.0. Data analisis dengan rumus korelation produk moment. Haislnya analisis data menunjukan 1) prestasi belajar siswa kategori rendah yaitu 67,8\% 2) kegiatan ekstrakurikuler pramuka kategori cukup baik yaitu 73\% dan 3)ada punya hubungan yg signifikandiantara kegiatanektrakurikuler pramuka sama prestasii bljara murid SMAN 1 X Koto Singkarak yaitu $r$ hitung 0,728> r tabel 0,24 dannilai thitung $8,495>$ tTabel 1,980 di taraf [ercaya $95 \%$ hasilnya yaitu adalah terdapatnya hubungan yg artinya antara kegiatan ekstrakurikuler pramuka dengan prestasi belajar siswa di SMAN 1X Koto Singkarak. Artinya kegiatan ekstrakulikuler pramuka merupakan salah satu fktor yang mempengarhi prestasi belajar murid di SMAN 1 X Koto Singkarak.
\end{abstract}

Kata Kunci: Kegiatan Ekstrakurikuler Pramuka dan Prestasi Belajar Siswa

How to Cite: Saputra,Oki ${ }^{1}$, Hadiyanto ${ }^{2}$,Ahmad Sabandi ${ }^{3}$, Lusi Susanti ${ }^{4} .2021$.Hubungan Kegiatan Ekstrakurikuler Pramuka dengan Prestasi Belajar Siswa di SMAN 1 X Koto Singkarak. Journal of Education Administration and Leadership Vol (N): pp. XX-XX, DOI: 10.24036/XXXXXXXXXX-XXX 


\section{Pendahuluan}

Setiap peserta didik dibekali kemampuan dan potensi yg beda yaitu tumbuh dan kembang. Baik intelegensi, semangat balajarnya, keinginan belajaranya dan lainnya. Jika dihubungkandengan aktif dalam ekskul, murid aktif memilih berprestasi dalam belajar dibandingkan murid yang tidak aktif organisasi. Adapun yang emmepengaruhi murid yaitu, terdiri dari sebab internal dan ekstrenal, dimana internal seperti jasmani, psikolog,kelelahan. Sedangkan eksternal seperti keluarga, sekolah dan masyarakat. Faktor-fakor tersbut dapat tercermin dalam suatu kegiatan pendidikan di bidang ekstrakurikuler.Pada kegatan ini urid dpt mengembangkan minat dan bakatnya. Selain itu ia juga belajar dari lingkungan belajar yang terbentuk dari kegiatan ekstrakurikuler. Tujuan mengembangkan diri yaitu untuk memberi kesempatan pada murid mengekspresikandiri sesuai kebutuhan, potensi, kemampuan, keinginan, serta perkembanganmurid sesuai kondisi sekolah. tujuan lainnya untuk menunjang pendidikan murid dalam mengembangkan kreativutas dan minat, bakat, kompetensi, wawasan, karier, dan kemandirian (Mumuh Sumarna, 2006).

Kegiiatan ekstrakrikuler yg di ikuti serta dilaksanakan oleh murid baik di sekolah atau luar, gunanya supaya siswa kaya dan mau memperluas diri. Diantaranya kegiatan ekstkurikuler pramuka yang mampu melatih dan menumukan nilai nilai dan karakter siswa. Pend pramukaa yaitu proses pendidikan luhur yang lengkapi sekolah dan keluarga dnegan bentuk menarik, menyenangkan, sehat, teratur, praktiis dialam terbua dengan priinsip dasar kepramukan dan metode kepramukan dg sasaran akhir membentuk watak, akhlak dan budi pekerti.

Saat proses belajar sering ditemui murid yang tidak berprestasi setara dengan kemampuan inteligensinya. Ada juga yang punya inteligensi tinggi tapi prestasi belajar rendah, tapi ada juga yang inteligensi rendah tapi bisa meraih prestasi belajar. Pada proses mengajar murid, kedua inteligensi sangat dibuthkan. IQ tidak dapat berkerjabaik tanpa penghayatan emosional terhadap pembelajaran yang dijelaskan. Keseimbangan IQ dan EQ adlaah kuci sukses individu dalam prestasi belajar membangn karir. go(Goleman, 2004). E Q Q dapat emenentukan keberhasilan indvidu dalam presatsi belajar dan membangun sukses karir, mengembangakn minat dan dapat mengurangi agresivitas bagi remaja.

Akademik yang dicapai murid adaalh interaksi beberapa faktor dari diri sendiri maupun dari luar. Kegiatan ekskul adalh rangkaian kegiatan belajar diluar pelajaran terprogram, yaitu gunanya untuk meningkatakan wawasan siswa,tumbuhkan keinginan dan serta abdi masyarakat. Kegiatan ekskul ini diharapakan dapat meningkatkan prestasi akademik, karena dapat mengambangkan aspekk efektif dan psikomotor siswa. Dan prilkau belajar dapat mempengaruhi prestasi akademik siswa..

Namun pada kenyataannya berdasarkan pengamatan yang peneliti lakukan pada bulan September 2019 kemarin, peneliti melihat 1) siswa mengikuti kegiatan ekstrakurikuler pramuka bukan berdasarkan minat dan bakat melainkan atas ajakan teman sebaya atau senior, sehingga siswa kurang mampu mengembangkana kemampuannya, 2) siswa ikut dan terdaftar dalam suatu kegiatan ekstrakurikuler namun belum terlibat secara penuh dalam kegiatanya, 3) siswa beranggapan bahwa mengikuti kegiatan ekstrakurikuler pramuka tidak memberikan pengaruh dan manfaat bagi mereka, 4) murid yang aktif ekstrakurikuler pramuka kurng mampu dlam mengatur wktu antara berorganisasi dan belajar, dan 5) siswa yang blum mengeti manfaatt dan maksud ikut ekstrakurikuler.

Berdasarkan beberapa uraian tersebut riset ini berguna agar adanya info tentang adakah hubungan kegiatan ektrakurikuler pramuka dngan prestaisi belajar siswa di SMA N 1 X Koto Singkarak.

\section{Metode Penelitian}

riserch ini merupakan korelasional yang melihat terdapatnya hubunga kegiatan ekstrakurikulerr pramuka dengan presstasi blajar siswa. Populais pada yaitu keseluruhan siswa yang mengikuti ekstrakurikuler pramuka di SMAN 1X Koto Singkarak berjumlah 228 orng. Sample penelitian ini berjumlah 66 orang dengann cara rumus Slovin lalu ambil teknik proportional stratified rendom sampilng. Intrumen telti dgunakan angkte sekala liker dengan 5 pilihan yang telah di ujivaliditas dan relibilitas yang dibantu SPSS 16.0. datanya dianalisis dengan rumus korelasi Product Moment yang dinyatakan dari (Suharsimi Arikunto, 2014) yakni:

$$
r_{x y}=\frac{N(\Sigma x y)-\left(\Sigma_{x}\right)\left(\Sigma_{y}\right)}{\sqrt{\left\{N \Sigma x^{2}-(\Sigma x)^{2}\right\}\left(N \Sigma y^{2}-(\Sigma y)^{2}\right\}}}
$$


Ket:

$\mathrm{r}_{\mathrm{xy}}=$ koefsien korelasii variabel $\mathrm{x}$ dan $\mathrm{y}$

$\mathrm{N}=$ jumalh respond

$\mathrm{x}=$ Skor untuk variabel $\mathrm{x}$

$\mathrm{y}=$ skor untuk variabel $\mathrm{y}$

$\mathrm{xy}=$ jumlah pengalian $\mathrm{x}$ dan $\mathrm{y}$

$\mathrm{x}^{2}=$ Jmlah kuadrat dan $\mathrm{x}$

$\mathrm{y}^{2}=$ jumalh kuadratdari $\mathrm{y}$

\section{Hasil dan Pembahasan}

Data riset terkait hubungan kegiatanekstrakkurikuler pramuka dengan prestasi belaajar siswa di SMAN 1X Koto Singkarak yang dapat dilihat sebagai berikut:

1. Data Kegiatan Ekstrakurikuler Pramuka

Skor kegiatan ekstrakurikuler pramuka yang ditemukan menyebar dari poin minimal 75 mencapai 137, padahal kategori minm30 dan skor ideal150. Berdasarkan hasl pengerjaan datasecara standar, maka didapatkan poin rata-rata 109,6, nilai tengah 108,79, poin yang sering muncul 107,17, serta simpangan baku 16,56.

Tabel 1. Distribusi Frekuensi Data Variabel Kegiatan Ekstrakurikuler Pramuka

\begin{tabular}{|c|c|c|c|}
\hline Class Interval & F & $\begin{array}{c}\text { \% Frekuensi } \\
\text { Absolut }\end{array}$ & $\begin{array}{c}\text { Frekuensi } \\
\text { Relative }\end{array}$ \\
\hline $129-137$ & 12 & $18,18 \%$ & \multirow{2}{*}{$54,38 \%$} \\
\hline $120-128$ & 11 & $16,6 \%$ & \multirow{2}{*}{$12,12 \%$} \\
\hline $111-119$ & 13 & $19,6 \%$ & \multirow{2}{*}{$33,17 \%$} \\
\hline $\mathbf{1 0 2 - 1 1 0}$ & $\mathbf{8}$ & $12,12 \%$ & \\
\hline $93-101$ & 11 & $16,6 \%$ & $\mathbf{1 0 0 \%}$ \\
\hline $78-101$ & 3 & $12,12 \%$ & \\
\hline Jumlah & $\mathbf{6 6}$ & $\mathbf{1 0 0 \%}$ & \\
\hline
\end{tabular}

Berdasarkan Tabel 1 di atas, maka 54,38\% responden menyatakan bahwa kegiatan ekstrakurikuler pramuka di SMAN 1X Koto Singkarak di atas poin pertengahan, sementara itu sejumlah 12,12\% responden sepakat kegiatan ekstrakurikuler pramuka mampu dibawah poin rata-rata, dan 33,17\% kegiatan ekstrakurikuler pramuka di SMAN 1X Koto Singkarak berada pada skor rata-rata.

Berlandaskan pengolahan data angket varibael kegiatan ekstrakurikuler pramuka (X) caranya bandingkan poin mean dengan poin maks di-X 100, dapatlah nilai mean 109,6 dibagi dengan poin maks 150 , maka didapati angka $0,730 \times 100=73$. Hal ini berarti kegiatan ekstrakurikuler pramuka di SMAN $1 X$ Koto Singkarak terdapatnya kategorie "cukup baik" yakni $73 \%$.

Untuk melihat rata-rata per indikator dari kegiatan ekstrakurikuler pramuka bisa dicek pada table 2.

Tabel 2. Tingkat Capaian Per Indikator Kegiatan Ekstrakurikuler Pramuka

\begin{tabular}{|c|l|c|c|c|}
\hline No & Indicator & Rata - rata & $\begin{array}{l}\text { Tingkatan } \\
\text { Capaian }\end{array}$ & Categori \\
\hline 1. & Keaktifan & 3,69 & $74 \%$ & Cukup \\
\hline 2. & Individu & 3,69 & $74 \%$ & Cukup \\
\hline 3. & Kehadiran & 3,67 & $73 \%$ & Cukup \\
\hline & Rata-rata total & $\mathbf{3 , 6 8}$ & $\mathbf{7 3 , 6 \%}$ & Cukup \\
\hline
\end{tabular}

Berdasarkan tabel 2 dapat dilihat bahwa skor tertinggi terdapat pada indikator keaktifan dan indikator individu yaitu 74\%. Sedangkan skor terendah terdapat pada indikator kehadiran yaitu $73 \%$. Secara umum skor rata-rata kegiatan ekstrakurikuler pramuka di SMAN 1X Koto Singkarak adalah 73,6\%. Artinya secara umum kegiatan ekstrakurikuler pramuka di SMAN 1X Koto Singkarak sudah dikatakan baik. Maka dari itu, untuk skor terendah yaitu kehadiran di SMAN 1X Koto Singkarak di perlu 
diperhatikan dan ditingkatkan lagi, begitu juga dengan indikator yang lain semuanya harus ditingkatkan lagi.

\section{Data Prestasi Belaajr Siswa}

Skor prestasi belajar siswa terdapat penyebaran poin minim 70 sampai dengan 132,sedangkan kategori terindah 30 dan poin ideal 150 . Berdasarkan hasil data secara standar, maak didapati poin ratarata 101,82, skor tengah 102,04, nilai ynag sering muncul 102,48, lalu simpangan baku 14,85.

Tabel 3. Distribusi Frekuwensi Data Variabel Prestasi Belajar Siswa

\begin{tabular}{|c|c|c|c|}
\hline Class Interval & F & \% Frekuensi Absolut & Frekuensi Relatif \\
\hline $124-132$ & 4 & $6,06 \%$ & \multirow{2}{*}{$43,84 \%$} \\
\hline $115-123$ & 12 & $18,18 \%$ & \\
\hline $106-114$ & 12 & $18,18 \%$ & $19,6 \%$ \\
\hline $\mathbf{9 7 - 1 0 5}$ & $\mathbf{1 3}$ & $19,6 \%$ & \multirow{2}{*}{$37,84 \%$} \\
\hline $88-96$ & 12 & $18,18 \%$ & \\
\hline $79-87$ & 9 & $13,6 \%$ & $\mathbf{1 0 0 \%}$ \\
\hline $70-78$ & 4 & $6,06 \%$ & $\mathbf{1 0 0 \%}$ \\
\hline Jumlah & $\mathbf{6 6}$ & & \\
\hline
\end{tabular}

Berdasarkan Tabel 3 di atas, maka 43,84\% responden menyatakan bahwa prestasi belajar siswa di SMAN 1X Koto Singkarak diatas skor rata-rata, sementara sebanyak 19,6\% respond mengtarakan prestasi belajar siswa berada di bawah skor rata - rata, dan 37,84\% prestasi belajar siswa pada skor ratarata.

Berdasarkna pengolahan angket variabel prestasi belajar siswa (Y) dengan bandingkan skor (mean) sama skor maksimal dikali 100, maka nilai mean 101,82dibagi dengan skor maksimal 150, maka diperoleh angka $0,678 \times 100=67,8$ artinya prestasi belajar siswa di SMAN 1X Koto Singkarak berada pada kategori "rendah" yaitu sebesar $=67,8 \%$.

Untuk mengetahui rata-rata setiap indikator dari prestasi belajar siswa dapat dilihat pada Tabel 4.

Tabel 4. Tingkat Capaian Per Indikator Prestasi Belajar Siswa

\begin{tabular}{|l|l|c|c|c|}
\hline \multicolumn{1}{|c|}{ No } & \multicolumn{1}{|c|}{ Indicator } & Rata - Rata & $\begin{array}{c}\text { Tingkatan } \\
\text { Pencapaian }\end{array}$ & Categori \\
\hline 1. & Keteraturan & 3,57 & $71 \%$ & cukup tinggi \\
\hline 2. & Disiplin & 3,69 & $74 \%$ & Cukup tinggi \\
\hline 3. & Konsentrasi & 3,55 & $71 \%$ & cukup tinggi \\
\hline & Rata-rata total & $\mathbf{3 , 6 0}$ & $\mathbf{7 2 \%}$ & Cukup tinggi \\
\hline
\end{tabular}

Berlandaskan tabel 4 didapati poin maksima terdapat pada indikator disiplin yaitu $74 \%$. Sedangkan skor terendah terdapat pada indikator konsentrasi dan keteraturan yaitu $71 \%$. Secara umum skor rata-rata prestasi belajar sswa di SMAN 1X Koto Singkarak adalah 72\% artinya secara umum prestasi belajar siswa diSMAN 1 X Koto Singkarak sudah dikatakan cukup tinggi. Maka dari itu, untuk skor terendah yaitu konsentrasi dan keteraturan siswa dalam belajar perlu diperhatikan dan ditingkatkan lagi, begitu juga dengan indikator yang lain semuanya harus ditingkatkan lagi.

\section{Uji Normalitas Data}

Maka diperoleh hasil perhitungan kedua variabe kegiatan ekskul pramuka dengan prestsi belajar siswa bisa dicek pada tabel 6 .

Tabel 6. Rangkuman hasil dari uji normalitas Data

\begin{tabular}{|c|c|c|c|c|}
\hline \multirow{2}{*}{ Variabel } & & $\chi^{2}$ Tabel & & Penafsiran \\
\cline { 3 - 3 } & $\chi^{2}$ Hitung & $\alpha=0,05$ & Db & \\
\hline $\begin{array}{c}\text { Kegiatan Ekstrakurikuler } \\
\text { pramuka }\end{array}$ & 9,38 & 9,488 & 4 & Normal \\
\hline Prestasi belajar siswa & 9,265 & 9,488 & 4 & Normal \\
\hline
\end{tabular}

Pada Tabel 6 terlihat bahwa x2 hitung yg diperolehpada uji normalitas di atas lebih kecill dari $\chi^{2}$ table pada taraf signifikan yang digunakan $\alpha=0,05$. berarti kedua variabel (X) dan variabel (Y) berdistribusi normal. 
4. Pengujian Hipotesis

Hasil yang diperoleh $\mathrm{r}_{\text {hitung }}=0,728>\mathrm{r}_{\text {tabel }}=0,24$ pada tingkat kepercayaan95\%, dengan demikian dapat diartikan terdapat hubungan kegiatan ekstrakurikler pramukadengan prestasi blajar murid SMAN 1X Koto Singkarak.

Untuk melihat keberartian hubungan variabel X dan Y maka dilakukan uji coba t. Berdasarkan hasil perhitungan diperoleh $t_{\text {hitung }}=8,495>t_{\text {tabel }}=1,980$ dengan taraf kepecayaan $95 \%$. Dengan demikian, yakni disimpulkan bahwa terdapatnya hubungan kegiatan ekstrakurikuler pramuka dengan prestasi blajar murid di SMAN 1 X Koto Singkarak. Hasi perhitungan bisa dicek pada tabel 7 sebagai berikut:

Tabel 7. uji korelasi dan keberartian korelasi variabel $X$ dan $Y$ dengan Uji $\mathbf{r}$ dan Uji $t$

\begin{tabular}{|c|c|c|c|c|}
\hline $\begin{array}{c}\mathrm{r}_{\text {hitung }} \\
\text { Product } \\
\text { Moment }\end{array}$ & $>$ & $\mathrm{r}_{\text {tabel }}$ & \multirow{2}{*}{$\mathrm{t}_{\text {hitung }} \mathrm{Uji} \mathrm{t}$} & $\mathrm{t}_{\text {tabel }}$ \\
& $\alpha=0,05$ & & $\alpha=0,05$ \\
\cline { 2 - 3 } & 0,728 & 8,49 & & 1,980 \\
\hline
\end{tabular}

Berdasarkan hasil pengujian pada Tabel 7, hipotesis penelitian ini berbunyi "terdapatnya hubungan berarti kegiatan ekstrakurikuler pramuka dengan prestasi beljar murid di SMAN 1X Koto Singkarak". Dengan demikian, bisa disimpulkan bahwa terdapat hubungan yang berarti antara kegiatan ekstrakurikuler pramuka dengaan prestasi belajar siswa di SMAN 1X Koto Singkarak.

\section{Pembahasan}

Hasil riset terkait dorongan Hubungan Kegiatan Ekstrakurikuler Pramuka dengan prestasi belajar siswa di SMAN 1X Koto Singkarak yaitu:

1. Kegiatan ektrakurikuler pramuka

hasil penelitian diperoleh indikator kehadiran yang memiliki tingkat capaian terendah. Hal ini disebab kan karena siswa tersebut mengikuti kegaiatan ekstrakurikuler pramuka tidak berdasarkan keinginannya sendiri, namun karena ikut ikutan teman. Perlunya ditegaskan peraturan mengenai kedisplinan siswa untuk mengikuti pramuka agar tingkat kehadiran siswa yang mengikuti pramuka menjadi lebih baik. Menurut (Hadiyanto, 2013) pembinaan kesiswaan yaitu upaya yang dilakukan sekolah melalui aktifitas-aktifitas pesdik diluarjam pelajaran dikelas untuk menguasai agar pesdik bisa tumbuhdan berkemlbang sebgai manusya yang sesungguhnya seperti tujuan penddikan nasional lalu idelogy Negara. Indikator keaktifan dan individu juga perlu diperhatikan kembali demi kelangsungan proses belajar dan mengajar agar mendapatkan hasil pembelajaran yang lebih baik lagi dan memuaskan. Untuk itu, diingikan setiap sekolah harus memiliki program ekskul yang akan dilakukan dan berguna sebaik mungkin.

Kegiatan ekstrakurikuler pramuka disekolah dilakukan secara individali agar dapat memberikan hasil terhadap peningkatan pengetahuan, penyaluran bakat minat siswa, sedangkankegiatan ekskul ynag dilaksanakan secara berkelompok bisa menhasilkan wadah dalam rangka pembinaan terhadap pengabdian kemasyarakat.

2. Prestasi belajar siswa

Dari hasil penelitian yang telah dilakukan diperoleh indikator keteraturan dan konsentrasi yang memiliki tingkat capaian skor terendah. Keteraturan menurut (Gie, 1985) adalah Belajar yang dilakukan secarateratur yang akan memproleh hasil baik. Ketraturan melputi kebiasaaan kegiatan pembelajaran secara teratur, mensimpan dan memelihara secara tratur alat perlengkapan untuk belajar, lalu kebiasaan membaca buku - buku pelajaran.Jika sifatkteraturan ini telah benar - benar di hayati oleh siswa, sehinggaa menjadi sebuah kebiasaaan, maka sifat ini akan mempengaruhi pula jalan pikiran yangteratur untuk menuntut ilmu.

Konsentrasi yakni kegiatan memfokuskan pikiran terhadap suatu perkara dengan mengenyampingkan seluruh perkara yang lainnya yang tidak berkepentingan. Dalam proses pembelajaran berkonsentrasi bermakna memfokuskan pikiran mengenai suatu mapel dengan mengenyampingkan selurh perkara yang tidak penting tersebut. Konsentrasi sangat kuat akibatnya terhadap proses dan hasil belajar yang dilakukan. Seseorang tidak akan sukses menghayati bahan mata pelajaran yang sedang digali jika usaha itu dikerjakan tanpa berkonsentrasi. Semua ketertarikan mesti dituangkan kepada apa yang wajib dan sedang berlangsung. Jika konsentrasi tidak ada maka memfokuskan pikiran dalam 
melaksanakan sesuatu atau belajar maka tidak akan batas akhir yang maksimal. Oleh karena itu, indikator keteraturan dan konsentrasi perlu diperhatikan kembali demi kelangsungan proses belajar dan mengajar agar mendapatkan hasil pembelajaran yang memuaskan.

3. Hubungan kegiatan ekstrakurikuler pramuka dengan prestasi belajar siswa

(Muhibbin, 2008) menjelaskan bahwasanya hubungan kegiatan ekstrakurikuler akan dapat terwujud dalam karakter berlatih siswa kebanyakan sering terlihat dalam peralihan yakni:

a) kelaziman, kebiasaan ini dapat terlihat dari cara belajar siswa yang selalu belajar walaupun sedang mengikuti kegiatan ekstrakurikuler. Hal tersebut bisa terjadi karena belajar telah menjadi kebiasan bagi siswa.

b) Keterampilan, keterampilan siswa dapat terlihat dari kegiatan apa yang dilakukan dalam program ekstrakurikurikulernya.

c) Pengamatan,maksudnya adalah keuntungankeahlian beljar seorang siswa, bisa mencapai pengamatan yang nyata objektif sebelum mencapai ketahap pengetahuan. Jadi seorang siswa dapat belajar dari pengamatan yang ia lihat dalam pelaksanakaan kegiatan ekstrakurikuler pramuka.

d) Berpikir rasional dan kritis adalah perwujudan perilaku belajar siswa terutama yang bertalian dengan pemecahan masalah. Dalam kegiatan ektrakurikuler, siswa diajarkan berbagai cara dalam menghadapi berbagai masalah yang akan dihadapi dan mengambil keputusan disetiap kegiatan yang dilakukan. Secara tidak langsung, maka akan berpengaruh kepada prilaku belajar siswa tersebut dikelas.

e) Inhibisi, yaitu kesanggupan siswa untuk mengurangi atau menghentikan tindakan yang tidak perlu, lalu memilih atau melakukan tindakan lainnya yang lebih baik ketika ia berinteraksi dengan lingkungannya. Siswa akan mengentikan kegiatan ekstrakurikulernya apabila ia merasa bahwa kegiatan tersebut mengganggu dalam proses belajar mengajarnya disekolah ( formal) atau dirumah

f) Tingkah laku efektif, watak yang seperti ini tidak terlerai dari dampak pengalaman belajar yang dialami para siswa. Oleh sebab itu, ia juga dapat dianggap sebagai pengaktualan karakter belajar.

Berlandaskan dari penjelasan di atas untuk menumbuhkan sikap kecerdasara, pengetahuan serta keterampilan demikian pula menyangkut peningkatan prestasi belajar siswa untuk itu perlunya pihak yang bersangkutan dalam lembaga pendidikan harus memadukan antara kegiatan intrakurikuler dengan ekstrakurikuler karena keduanya saling berkaitan atau korelasi.

\section{Kesimpulan}

Hasil penelitian dan pengujian hipotesis tentang hubungan kegiatan ekstrakurikuler pramuka dengan prestasi belajar siswa di SMAN 1X Koto Singkarak dapat diambil kesimpulan sebagai berikut:

1. Kegiatan ekstrakurikuler pramuka dengan prestasi belajar siswa di SMAN 1X Koto Singkarak berada pada kategori cukup baik yaitu dengan memperoleh skor $73 \%$. Artinya kegiatan ekstrakurikuler pramuka perlu ditingkatkan lagi agar pembina pramuka dapat melaksanakan tugasnya dengan baik dan benar.

2. Prestasi belajar siswa di SMAN 1X Koto Singkarak berada pada kategori rendah yaitu mendapatkan skor $67,8 \%$. Artinya prestasi belajar siswa belum sesuai dengan harapan, Namun perlu adanya dilakukan peningkatan agar lebih baik lagi.

3. Terdapat hubungan yang signifikan antara kegiatan ekstrakurikuler pramuka dengan prestasi belajar siswa di SMAN 1X Koto Singkarak dengan perhitungan rhitung $=0,728>$ rtabel 0,24 pada taraf kepercayaan 95\%. Pada keberartian korelasi terdapat hubungan yang signifikan antarakegiatan ekstrakurikuler pramuka dengan prestasi belajar siswa di SMAN 1X Koto Singkarakyaitu $t$ hitung $8,495>t$ tabel 1,980 pada taraf kepercayaan $95 \%$. Dengan demikian hipotesis yang diuji dapat diterima.

Berdasarkan kesimpulan di atas dapat dikemukakan saran-saran sebagai berikut:

1. Bagi pihak sekolah, hendaknya lebih memberi perhatian pada peningkatan pada kegiatan ekstrakurikuler pramuka guna untuk meningkatkan prestasi belajar siswa sehingga tujuan dari pembelajaran tercapai dengan baik. semakin baik kegiatan ekstrakurikuler pramuka maka akan semakin meningkat pula prestasi belajar siswanya.

2. Bagi guru, hasil penelitian ini dapat dijadikan sebagai bahan masukan agar diharapkan mampu membimbing siswa ke arah yang lebih dan mampu memberikan motivasi kepada siswa untuk belajar.

3. Bagi siswa, untuk dapat meningkatkan prestasi belajar melalui keteraturan dalam belajar dengan cara disiplin dalam pembelajaran serta konsentrasi yang pesat dalam belajar agar mendapat hasil belajar yang memuaskan. 
Oki Saputra $^{1}$, Hadiyanto ${ }^{2}$, Ahmad Sabandi $^{3}$, Lusi Susanti ${ }^{4}$ Hubungan Kegiatan Ekstrakurikuler Pramuka dengan Prestasi Belajar Siswa di SMA N 1 X Koto Singkarak

4. Bagi pembaca dan peneliti selanjutnya, semoga skripsi ini bermanfaat bagi peneliti selanjutnya dan bisa dijadikan sebagai panduan dalam meneliti kedua variabel yang sama untuk penelitian lanjutan yang relevan dengan tempat dan indikator yang berbeda

\section{Daftar Rujukan}

Gie, T. L. (1985). Cara Belajar Yang Efisien. PKS.

Goleman, D. (2004). Kepemimpinan Berdasarkan Kecerdasan Emosi (Primal Leadership). PT. Gramedia Pustaka Utama.

Hadiyanto. (2013). Manajemen Peserta Didik Bernuansa Pendidik Karakter. AL-Wasat.

Muhibbin, S. (2008). Psikologi Pendidikan. Remaja Rosdakarya.

Mumuh Sumarna. (2006). Perbandingan Antara Siswa Yang Mejadi Pengurus dan Bukan Pengurus OSIS Dalam Pemanfaatan Waktu Luang dan Prestasi Belajar di SMK N 6 Bandung. Jurnal Psikologi.

Suharsimi Arikunto. (2014). Prosedur Penelitian Suatu Pendekatan Praktik. Rineka Cipta. 